\title{
Contribution to the Validation of the Kutcher Adolescent Depression Scale (KADS-6) in a Portuguese Population
}

\author{
Contribuição para a Validação da Kutcher Adolescent Depression Scale (KADS-6) \\ para a População Portuguesa
}

\author{
Sónia Quintão ${ }^{*}{ }^{a}$, Sónia David ${ }^{b}$, Ricardo Gusmão $^{a} \&$ Stanley Kutcher ${ }^{c}$ \\ ${ }^{a}$ Faculdade de Ciências Médicas da Universidade Nova de Lisboa, Lisboa, Portugal, \\ ${ }^{b}$ Universidade Lusófona de Humanidades e Tecnologias, Lisboa, Portugal \\ $\&{ }^{c}$ Dalhousie University, Halifax, Canada
}

\begin{abstract}
The KADS-6 is a self-report assessment instrument known for its ease application in assessing depression in young people. This study aimed to contribute to the validation of the Portuguese version of this tool and analyze its psychometric characteristics in comparison with other self-report instruments for depression in adolescents, in Portugal. Two samples were collected, a non-clinical group of in school youth ( $n=773 ; 52.4 \%$ male) and a clinical sample ( $n=134$ youth; $44 \%$ male). Comparisons also used the Beck Depression Inventory (BDI-II) and the Children's Depression Inventory (CDI). Results: The factor analysis revealed the unidimensionality of the measure. The KADS-6 demonstrated good internal consistency (Cronbach's alpha) in both clinical (.74) and school (.80) samples. Its convergent validity with the BDI-II and CDI was $r=.44 ; r=.61$, respectively in the clinical sample and $r=.60 ; r=.57$ in the school sample. The KADS-6, a short and time efficient instrument, showed good psychometric characteristics in terms of internal consistency and convergent validity in comparison with the BDI-II and the CDI. Given its ease of use and scoring, the KADS-6 could be considered for use in both school and clinical settings when addressing adolescent depression. Keywords: Adolescence, depression, assessment, measure development/validation.
\end{abstract}

\begin{abstract}
Resumo
A Kutcher Adolescent Depression Scale (KADS-6) é uma medida de autorrelato, conhecida pela sua facilidade de aplicação na avaliação da depressão em jovens. Este estudo teve como objetivos contribuir para a validação da versão portuguesa desta ferramenta e analisar as suas características psicométricas em comparação com outros instrumentos de autorrelato para a avaliação da depressão em adolescentes, em Portugal. Foram recolhidas duas amostras, uma não clínica, formada por jovens em contexto escolar ( $n=773 ; 52,4 \%$ rapazes) e outra amostra clínica ( $n=134 ; 44 \%$ rapazes). Foram também utilizados o Beck Depression Inventory (BDI-II) e o Children's Depression Inventory (CDI). A análise fatorial revelou a unidimensionalidade da medida. A KADS-6 demonstrou boa consistência interna (alfa de Cronbach) nas amostras não clínica (.74) e clínica (.80). A validade convergente com a BDI-II e CDI foi, respetivamente, $r=.44 ; r=.61$ na amostra clínica e $r=.60 ; r$ $=.57$ na amostra não clínica. Conclui-se que a KADS-6 mostrou boas características psicométricas em termos de consistência interna e validade convergente em comparação com o BDI-II e o CDI. Dada a sua facilidade de uso e interpretação, a KADS-6 pode ser considerada para uso em contexto escolar e em ambientes clínicos, para avaliar a depressão adolescente.

Palavras-chave: Adolescência, depressão, avaliação, desenvolvimento/validação de instrumentos.
\end{abstract}

Major depression is a common and impairing mental disorder, and globally is a leading source of disability, accounting for almost $11 \%$ of the global burden of disease and the third leading source of disability worldwide (Saluja et al., 2004; World Health Organization [WHO]

\footnotetext{
* Mailing address: Universidade Nova de Lisboa, Faculdade de Ciências Médicas, Campo Mártires da Pátria, 130, Lisboa, Portugal 1169-056. E-mail: sonia.quintao@ fcm.unl.pt
}

\& World Bank [WB], 2011). Its onset is commonly in the adolescent years and it leads to substantial short and long term morbidity including social, vocational/academic and interpersonal difficulties, increases risk for other mental disorders, substance abuse and a variety of other illnesses (such as diabetes and cardiovascular disease) and is a key risk factor for suicide (Bertolote, Fleischmann, de Leo, \& Wasserman, 2003; Goodwin, Kroenke, Hoven, \& Spitzer, 2003; Gusmão, Xavier, Heitor, Bento, \& Almeida, 2005; Kessler, Avenevoli, \& Ries Merikangas, 2001). A number 
of safe and effective treatments for depression in young people exist but many depressed youth are still neither identified, properly diagnosed nor receive appropriate care (Kessler et al., 2001; Leaf et al., 1996). It is thus essential that substantive attempts be made to identify and provide best evidence based treatments to young people with depression.

Since depressive symptoms associated with psychological distress or mental health problems are common in adolescents, considerable effort has been devoted to differentiating these from depressive disorders, and to screening for depressive disorders in young people so that early interventions for depressed youth can be most appropriately applied (Jensen, Cheung, Zuckerbrut, Ghalib, \& Levitt, 2007/2012; MacMillan et al., 2005; Saluja et al., 2004; Williams, O'Connor, Eder, \& Whitlock, 2008). Increasingly, school based interventions are being applied in an effort to help identify high-risk youth and engage those with depression in effective mental health care (Cooper, Clements, \& Holt, 2011; Cusimano \& Sameem, 2011; Ellonen, Kääriäinen, \& Autio, 2008; Kutcher \& Wei, 2012; Scott et al., 2010; Wei \& Kutcher, 2012).

Identification of depression in young people in school settings can be a difficult challenge, and a number of self-report tools have been developed to assist in that task (Cheung et al., 2010; Gray, Dubin-Rhodin, Weller, \& Weller, 2009). While their psychometric properties vary somewhat their utility in both population and clinical settings is related to numerous factors including but not limited to: acceptable sensitivity and specificity; ease of administration; acceptability to adolescents; ease of use; brevity of use; ease of scoring; availability in different languages; demonstrated applicability in different countries.

The KADS was developed to try to address most of these issues, to provide a brief, user-friendly, clinically useful and valid tool for assessment of adolescent depression. These characteristics enhance the probablilty of patient and clinician acceptance. This is the reason why the validation of this instrument in Portugal is important. We here report on the psychometric properties of the Kutcher Adolescent Depression Scale (KADS), a recommended population and clinical screening tool for depression in this age group (Jensen et al., 2007/2012) applied in a population of Portuguese adolescents.

\section{The Kutcher Adolescent Depression Scale}

The KADS was developed by adolescent mental health specialists, pediatricians and health researchers to assist in the identification and clinical care of Depression in young people aged 12 to 22 (LeBlanc, Almudevar, Brooks, $\&$ Kutcher, 2002). The initial studies of KADS were conducted on population samples of students attending secondary school, in healthcare clinics and of adolescent subjects in clinical research projects related to the diagnosis and treatment of Major Depressive Disorder.
There are three different versions of the KADS: a 6-item, an 11-item, and a 16-item version. While all three versions of the KADS can be used, extensive experience with the scale has demonstrated that the KADS-6 is the version most commonly used in everyday clinical settings, both to screen for possible depression and to monitor the outcome of interventions in youth diagnosed with and treated for depression (personal communication: SK). The KADS-6 is designed for use in institutional settings (such as schools or primary health care units), and can be used as a screening tool to identify adolescents at risk for depression by health care providers (e.g. public health nurses, primary care physicians) and educators in the school setting (e.g. school psychologists, social workers, counselors, etc.) to help assess young people who are at risk for or have been identified as possibly presenting a depressive disorder. KADS is a self-report measure intended to be completed independently by the youth after having been introduced to the scale by the health or human services provider using the KADS. The KADS is reading accessible at the sixth grade level, thus making it accessible to young people during the period in which depression is commonly diagnosed (DSM V). The KADS-6 is much briefer than other available adolescent depression scales and has been recommended for use in independent expert reviews, including the GLAD-PC Guidelines (U.S. and Canada; Jensen et al., 2007/2012). The KADS-6 has been translated into several different languages and is used globally (Kutcher \& Chehil, 2007a). It is freely available at: www.teenmentalhealth.org.

The six items of the KADS- 6 are rated using a fourpoint Likert scale (0-Hardly ever, to 3 -All of the time). A total item's summed score of six or more is consistent with a diagnosis of Major Depressive Disorder and should trigger a more comprehensive assessment of the mental health status of the youth completing the scale. The last item of the KADS-6 addresses suicide risk. Youth scoring one or higher on this item should undergo a more detailed suicide risk assessment (LeBlanc et al., 2002). Further, the construction of the KADS-6 (with the use of the phrase "Hardly Ever" as point zero) allows the clinician to probe for suicidal ideation if there is suspicion of increased risk even if the respondent has not endorsed a positive score on this item.

In the validation study of the scale, LeBlanc et al. (2002) compared the validity of the diagnosis by the full 16-item instrument, and shorter versions (6 and 11-items), against a score higher than 15 with the Beck Depression Inventory (BDI; Beck, Ward, Mendelson, Mock, \& Erbaugh, 1961) and the DSM-IV TR diagnostic category of Major Depressive Episode (MDE) defined by clinical evaluation using the evaluation semi-structured interview instrument, the Mini International Neuropsychiatric Interview (MINI, version 4.4; Lecrubier et al., 1997). The sample consisted of 1712 adolescent students from the 7 th to the 12 th grade. Firstly, participants completed the BDI and 309 had scores 
Quintão, S., David, S., Gusmão, R. \& Kutcher, S. (2015). Contribution to the Validation of the Kutcher Adolescent.

above 15. Of these 309 were invited to undergo further evaluation, 161 accepted, and completed the KADS, the $\mathrm{BDI}$ (for a second time) and a diagnostic interview using the MINI for diagnosis of MDE. A receiver operating characteristic (ROC) analysis was performed to determine which KADS items most accurately identified participants with MDE. The ROC curve analysis showed that the KADS-6 was as effective as the BDI. Used with a cutoff of six, the KADS- 6 had rates of sensitivity and specificity of $92 \%$ and $71 \%$, respectively, a positive predictive value (PPV) of $10 \%$ for the total sample and $26 \%$ for the clinical sample and a negative predictive value (NPV) of $100 \%$ for the total sample and $99 \%$ for the clinical sample, values not reached by other assessment tools.

In a multicenter study (U.S. and Canada) Brooks, Krulewick and Kutcher (2003) obtained an internal consistency Cronbach's $\alpha$ of .80 for the KADS- $6, .84$ for the KADS-11 and .82 for the KADS-16, demonstrating good psychometric properties of the KADS-6 in diagnosis and treatment outcome capabilities in the clinical setting. Thus, the KADS- 6 has been validated in both population and clinical samples, making it a useful tool that can be applied across the continuum of care: from case identification to measurement of the outcomes of interventions.

\section{Other Self-Report Scales of Depression in Adolescents in the Portuguese Population}

There are a number of other self-report scales addressing depression in adolescents. The Beck Depression Inventory (BDI-II) is a 21-item tool often used in screening for depression (Beck, 1973; Beck, Steer, \& Brown, 1996; Gray et al., 2009; Oliveira-Brochado \& Oliveira-Brochado, 2008; Osman, Barrios, Gutierrez, Williams, \& Bailey, 2008). Its scores are often expressed as ranges apparently related to degrees of depression severity (mild, moderate, severe) but the utility and validity of this differentiation has not been substantively demonstrated. A validation study of the BDI-II with an adolescent Portuguese population $(n=775)$ was performed by Martins (2000) who obtained a Cronbach alpha of .89, a value suggestive of good internal consistency but its length makes its clinical utility in adolescents challenging. The CDI (Kovacs, 1985) is a selfassessment tool targeting youth ages $7-17$ years, consisting of 27 items, divided into 5 factors: negative mood, interpersonal problems, ineffectiveness, anhedonia, and low self-esteem (Pullen, Modrcin-McCarthy, \& Graf, 2000). The total score is calculated by summing all items and can range from 0 to 54,15 being the threshold value (Kovacs, 1985). The CDI has been used in various studies and ethnic populations (DeRosa \& Logsdon, 2006). A psychometric study of the CDI in the Portuguese population has been carried out by Cardoso, Rodrigues and Vilar (2004), but concerns about its poor discriminant validity, high rate of false-negatives and its relatively narrow age range suggest weak psychometrics and limited applicability (Cole \& Martin, 2005; Kovacs, 1985; Myers \& Winters, 2002) while its length makes its utility in adolescents challenging.
Aims of the Study

The main objective of this study was to analyze the psychometric characteristics of the Portuguese version of the KADS-6 and compare it with other measures of depression in adolescents previously validated in Portugal in this group (BDI-II and CDI). In this way we intended to verify the unidimensionality of KADS-6 and analyze its internal consistency.

We hypothesised that the KADS-6 would: (a) demonstrate an internal consistency similar to the BDI-II and $\mathrm{CDI}$; (b) be reasonably correlated with the BDI-II and CDI.

\section{Material and Method}

\section{Participants}

The study design is a cross-sectional survey. Two convenience samples were collected. A first sample of 773 non-clinical adolescents in a school setting in the WestCentral Region of Portugal, $44.7 \%$ male, mean age 15.9 years (range: 12 to 18 years; $S D: 1.37$ years), and a second, clinical sample of 134 adolescents in three youth oriented clinical settings in the northern region of Portugal, 52.6\% male, mean age 15.07 years (range: 12 to 18 years; $S D$ 1.37 years). A data collection tool was designed specifically for this study and included questions pertaining to demographic, social and school related items.

\section{Measures}

Depression was evaluated by the KADS-6 (LeBlanc et al., 2002), the Beck Depression Inventory (BDI-II; Beck et al., 1996), and the Child Depression Inventory (CDI; Kovacs, 1985), all described above.

The BDI-II and CDI, and the KADS-6, are all available in Portuguese. The KADS- 6 has been previously translated by RG who is a Portuguese native speaking, and backtranslated by an English native speaking translator and the final Portuguese version was adjusted for mental health constructs by RG and SK, mental health professionals with extensive clinical practice experience (Kutcher \& Chehil, 2007b; Appendix).

\section{Procedures}

A pre-study survey, addressing the feasibility of this approach was conducted with four teenagers, two males and two females. They were asked to read the protocol in order to critically determine the time required to complete it and to raise questions about its implementation. No substantive concerns were identified in this survey and accordingly the protocol as described above was implemented.

Following authorization and ethics review by the appropriate institutions, the study took place between April and June 2011. Informed consent was obtained from all participants as well as their legal guardians. Instructions were the same in both groups. The instruments were applied in the following order: KADS-6, BDI-II and CDI, with each application taking on average 20 minutes to complete. In the non-clinical sample, the completion of 
the survey took place in the school classroom, under the supervision of one of the authors $(S D)$.

Data collected were entered in a database, and statistical procedures were performed using the Statistical Package for Social Sciences (SPSS) version 17.0 for Windows.

A factor analysis of the KADS-6 items was performed with varimax rotation, in order to test the unidirectionality of the instrument. This analysis was performed with the aim of comparing results of the Portuguese study to studies conducted in the English language. Reliability was calculated according to classical test theory (Kline, 2005). To examine convergent validity, a Pearson correlation between the three depression measures was performed.

\section{Results}

\section{Ecological Validity and Acceptability}

of the Portuguese KADS-6

The ecological validity of the KADS- 6 Portuguese version is reasonable. The overall response rate was $100 \%$, no questionnaires had to be discarded from analysis, and the applicability was good with 897 respondents (98.9\%) fully completing the scale. Field researcher reports noted that in both groups, students preferred the use of the KADS-6 and that it was completed in less time and with greater ease than other the BDI-II or the CDI.

\section{General Data on the Psychometrics} of the KADS-6 Portuguese Version

A factor analysis of the items of the KADS- 6 was performed with varimax rotation. Data is appropriate to execute this analysis, with $\mathrm{KMO}=.839$ and good sphericity with a significance test of Bartlett .000. The varimax results obtained support the unidimensionality of the measure (eigenvalue 2.948), with an explained variance of $49.14 \%$.

In order to study the KADS-6 validity and reliability and compare it with the other measures of depression, internal consistency was assessed. Table 1 presents the results obtained for Cronbach's $\alpha$, the average inter-item correlation and the range of item-total correlation for the clinical, non-clinical and total sample.

Table 1

Fidelity Measures of Depression

\begin{tabular}{|c|c|c|c|}
\hline & Cronbach's $\alpha$ & $\begin{array}{l}\text { Average inter-item } \\
\text { correlation }\end{array}$ & $\begin{array}{l}\text { Range of item-total } \\
\text { correlation }\end{array}$ \\
\hline \multicolumn{4}{|l|}{ Clinical sample } \\
\hline Depression - KADS & .80 & .400 & $.458-.611$ \\
\hline Depression - BDI & .86 & .320 & $.034-.676$ \\
\hline Depression - CDI & .91 & .279 & $.024-.700$ \\
\hline Dysphoria & .87 & .296 & $.298-.696$ \\
\hline Self-esteem & .75 & .218 & $.032-.626$ \\
\hline \multicolumn{4}{|l|}{ Non-clinical sample } \\
\hline Depression - KADS & .74 & .348 & $.367-.590$ \\
\hline Depression - BDI & .90 & .315 & $.297-.650$ \\
\hline Depression - CDI & .87 & .222 & $.180-.605$ \\
\hline Dysphoria & .84 & .267 & $.350-.636$ \\
\hline Self-esteem & .69 & .177 & $.121-.535$ \\
\hline \multicolumn{4}{|l|}{ Total sample } \\
\hline Depression - KADS & .78 & .384 & $.425-.628$ \\
\hline Depression - BDI & .90 & .334 & $.185-.633$ \\
\hline Depression - CDI & .89 & .242 & $.163-.643$ \\
\hline Dysphoria & .86 & .289 & $.341-.672$ \\
\hline Self-esteem & .70 & .187 & $.139-.561$ \\
\hline
\end{tabular}


Quintão, S., David, S., Gusmão, R. \& Kutcher, S. (2015). Contribution to the Validation of the Kutcher Adolescent.

In the clinical sample, all dimensions show adequate internal consistency, with Cronbach $\alpha$ values ranging from .75 (Self-esteem) to .91 (depression measured by the CDI). In the non-clinical sample, all dimensions show adequate internal consistency, with Cronbach $\alpha$ values ranging from .69 (Self-esteem) to .90 (depression measured by the BDI). In the total sample, all dimensions show adequate internal consistency, with Cronbach $\alpha$ values ranging from .70 (Self-esteem) to .90 (depression measured by the BDI).

The symptomatic response categories of "much of the time", "most of the time" and at "all of the time" are scored considerably higher in the clinical compared to the school (non-clinical) sample (evaluated with Qui-squared with $p$ $<.001$, in each group).

Table 2

Response Rates for Each Item

\begin{tabular}{|c|c|c|c|c|}
\hline & Hardly ever & Much of the time & Most of the time & All of the time \\
\hline & $\%$ & $\%$ & $\%$ & $\%$ \\
\hline \multicolumn{5}{|c|}{ Clinical sample } \\
\hline KADS1 & 47.0 & 24.2 & 22.0 & 6.8 \\
\hline KADS2 & 61.8 & 19.8 & 11.5 & 6.9 \\
\hline KADS3 & 37.4 & 29.0 & 23.7 & 9.9 \\
\hline KADS4 & 53.5 & 27.9 & 12.4 & 6.2 \\
\hline KADS5 & 38.5 & 30.0 & 20.0 & 11.5 \\
\hline KADS6 & 78.8 & 12.1 & 3.8 & 5.3 \\
\hline \multicolumn{5}{|c|}{ Non-clinical sample } \\
\hline KADS1 & 78.3 & 14.4 & 5.9 & 1.4 \\
\hline KADS2 & 86.1 & 9.6 & 3.2 & 1.2 \\
\hline KADS3 & 43.5 & 35.9 & 16.1 & 4.5 \\
\hline KADS4 & 83.7 & 10.9 & 4.3 & 1.1 \\
\hline KADS5 & 56.3 & 30.3 & 9.0 & 4.4 \\
\hline KADS6 & 94.0 & 3.7 & 1.2 & 1.1 \\
\hline \multicolumn{5}{|l|}{ Total sample } \\
\hline KADS1 & 73.7 & 15.8 & 8.2 & 2.2 \\
\hline KADS2 & 82.5 & 11.1 & 4.4 & 2.0 \\
\hline KADS3 & 42.6 & 34.9 & 17.2 & 5.3 \\
\hline KADS4 & 79.3 & 13.4 & 5.5 & 1.8 \\
\hline KADS5 & 53.7 & 30.3 & 10.6 & 5.4 \\
\hline KADS6 & 91.7 & 5.0 & 1.6 & 1.7 \\
\hline
\end{tabular}

In the clinical sample, depression measured by the KADS- 6 average scores are the double those in the nonclinical sample. In the other two scales, scores are much higher in the clinical sample, but the percentage differences are not as marked as in the KADS-6. The CDI is remarkable for the small differences between clinical and non-clinical samples (see Table 3). 
Table 3

Average, Standard Deviation and Ranges of Scores

\begin{tabular}{lccc}
\hline & KADS & BDI & CDI \\
\hline Clinical sample & & & 16.00 \\
$\quad$ Average & 4.66 & 18.30 & 9.74 \\
Standard deviation & 3.94 & 12.20 & $1-52$ \\
$\quad$ Interval & $0-18$ & $0-59$ & \\
Non-clinical sample & & & 10.75 \\
Average & 2.23 & 9.34 & 7.39 \\
Standard deviation & 2.59 & 8.90 & $1-52$ \\
Interval & $0-18$ & $0-59$ & \\
\hline
\end{tabular}

\section{Group Differences}

In order to investigate the existence of differences in scores between academic cycles, an analysis of variance, one-way ANOVA for three independent samples was used. There were statistically significant differences between the academic cycles, in the clinical sample, for depression measured by KADS- 6 with $F(2 ; 130)=5.335$, $p=.006$. To verify in which cycles the differences were most pronounced, a post hoc analysis, using the Tukey method was performed showing that students endorsed more depression during the second cycle of the $4^{\text {th }}$ year.

Table 4

Differences between Academic Cycles

\begin{tabular}{lccccccc}
\hline & $4^{\text {th }}$ Grade and $2^{\text {nd }}$ Cycle & \multicolumn{2}{c}{$3^{\text {rd }}$ Cycle } & \multicolumn{2}{c}{ High school } & $F$ \\
\cline { 2 - 7 } & $M$ & $S D$ & $M$ & $S D$ & $M$ & $S D$ & \\
\hline Clinical sample & 4.20 & 3.28 & 4.16 & 4.01 & 7.26 & 4.25 & $5.335^{*}$ \\
Non-clinical sample & 2.39 & 2.74 & 2.04 & 2.42 & 2.55 & 2.83 & 2.897 \\
\hline
\end{tabular}

$* p \leq .01$

In order to investigate differences between clinical and non-clinical samples an analysis using Student $t$ test for independent samples was performed. Differences were found between clinical and non-clinical participants with, $t(153)=6.747, p<.001(M=4.62, S D=3.94$ in clinical sample, $M=2.23, S D=2.59$ in non-clinical sample). These results confirmed that participants in the clinical sample exhibit more depressive symptoms than participants in the non-clinical sample.

\section{Correlations}

In the clinical sample, moderate positive and statistically significant correlations were found between total KADS-6 and total BDI and CDI scores, with correlation values of $(r=.44, p<.001)$ and $(r=.61, p<.001)$, respectively.

In the non-clinical sample, moderate positive and statistically significant correlations between the
KADS- 6 and total BDI and CDI were found, with correlation values of $(r=.60, p<.001)$ and $(r=.57, p$ $<.001)$, respectively.

In relation to both samples considered together, moderate positive and statistically significant correlations between the KADS- 6 and total BDI and CDI scores are found, with correlation values of $(r=.60, p<.001)$ and $(r$ $=.61, p<.001)$, respectively.

\section{Discussion}

We studied the psychometric characteristics of the KADS-6, in a mixed sample of Portuguese adolescents including youth in both clinical and non-clinical (school) settings, comparing it with other self-report measures of assessment of depression in adolescents. Our intention was to verify the unidimensionality of KADS-6, analyze the internal consistency of the KADS-6 compared with 
Quintão, S., David, S., Gusmão, R. \& Kutcher, S. (2015). Contribution to the Validation of the Kutcher Adolescent.

Table 5

Correlation between KADS-6, BDI and CDI $(p \leq .001)$

\begin{tabular}{lcc}
\hline & KADS & BDI \\
\hline Clinical sample & & \\
BDI & .44 & \\
CDI total & .61 & .73 \\
Non-clinical sample & & \\
BDI & .60 & \\
CDI total & .57 & .75 \\
Total sample & & \\
BDI & .60 & \\
CDI total & .61 & .76 \\
\hline
\end{tabular}

the BDI and CDI and assesses the convergent validity of the KADS-6.

Our results show the KADS- 6 to be a unidimensional measure with internal consistency as good as the other scales evaluated. This finding is consistent with other reports regarding the KADS-6 from North American samples (Brooks et al., 2003). Furthermore, the KADS-6 demonstrated better discrimination between clinical and non-clinical samples than the other two scales, suggesting it may be a better discriminant between common but not diagnostically significant depressive symptoms in this population.

Students in higher grades showed more depressive symptoms than those in lower grades, consistent with the known epidemiology of the onset of depression in this age group (Arnarson \& Craighead, 2011; Harrington, 2001; Pullen et al., 2000) and field note responses indicated greater youth comfort with, utility and brevity of use for the KADS-6 compared to the other options.

Our second hypothesis was that the KADS-6 scores would have a positive and significant correlation with BDIII and CDI scores. In congruence with previous studies (Brooks et al., 2003; LeBlanc et al., 2002), our results confirmed this hypothesis. The results show that there is convergent validity with total BDI and CDI scores in both clinical and non-clinical samples. However, this correlation is not very high. This may be because both other scales assess more symptom possibilities, many of which are commonly found in non-depressed youth and thus perhaps showing less discriminant value for depression. The poorer differentiation between clinical and non-clinical samples of the BDI-II and CDI compared to the KADS-6 supports this possibility.

Our study had a number of limitations. First, we did not compare any of the scales studied to the gold standard of a structured clinical interview to determine caseness. Second, although our total sample included both rural and urban settings it was not necessarily representative of the national population. We also did not conduct evaluations nor comparisons of temporal stability in this study.

Despite these limitations we consider that our findings support the use of the KADS- 6 in the diagnostic assessment of depression in young people in Portugal. This is consistent with studies reported from North America and Poland (Brooks et al., 2003; Mojs, Warchol-Biederman, \& Samborski, 2012). It demonstrates good psychometric properties, is easy to understand and its brevity and adolescent friendly language make it useful in both school and clinic settings. It better differentiates between clinic and non-clinic samples than either the BDI or the CDI. It is much shorter and takes less time to complete than either the BDI or the CDI and was the subject of many fewer queries from respondents during the application of the scales in both clinical and non-clinical settings. The use of a youth friendly six-item self-report scale with established specificity and sensitivity for depression may be preferred to longer and less diagnostically focused alternatives.

Future studies in Portugal could involve validation comparisons of these instruments against a diagnostic gold standard, such as the MINI or other semi-structured interview, temporal stability, as well as the scale's application across a wider age group and in more geographic locations.

\section{Significant Outcomes}

- KADS-6 presents a high internal consistency.

- KADS-6 efficiently differentiates between clinic and non-clinic samples.

- There is convergent validity with total BDI and CDI scores in both clinical and non-clinical samples.

- KADS-6 can be advantageously applied in Portuguese cultural settings to foster recognition of depression in youth.

\section{References}

Arnarson, E. O., \& Craighead, W. E. (2011). Prevention of depression among iceland adolescents: A 12 month followup. Behaviour Research and Therapy, 49(3), 170-174. doi:10.1016/j.brat.2010.12.008

Beck, A. T. (1973). The diagnosis and management of depression. Philadelphia, PA: University of Pennsylvania Press.

Beck, A. T., Steer, R. A., \& Brown, G. K. (1996). Manual for Beck Depression Inventory II (BDI-II). San Antonio, TX: Psychology Corporation.

Beck, A. T., Ward, C., Mendelson, M., Mock, J., \& Erbaugh, J. (1961). An inventory for depression. Archives of General Psychiatry, 4, 561-571.

Bertolote, J. M., Fleischmann, A., de Leo, D., \& Wasserman, D. (2003). Suicide and mental disorders: Do we know enough? British Journal of Psychiatry, 183(5), 382-383. doi:10.1192/ bjp. 183.5 .382

Brooks, S. J., Krulewicz, S. P., \& Kutcher, S. (2003). The Kutcher Adolescent Depression Scale: Assessment of its evaluative properties over the course of an 8-week pediatric pharmacotherapy trial. Journal of Child and Adolescent Psychopharma cology, 13(3), 337-349. doi:10.1089/104454603322572679 
Cardoso, P., Rodrigues, C., \& Vilar, A. (2004). Prevalência de sintomas depressivos em adolescentes portugueses. Analise Psicologica, 22(4), 667-675.

Cheung, A., Ghalib, K., Jensen, P. S., Kelleher, K. J., ReissBrennan, B., Tomb, M., ...Zucherbrot, R. (2010). Guidelines for adolescent depression in primary care (GLAD-PC) Toolkit. Version 2.

Cole, D. A., \& Martin, N. C. (2005). The longitudinal structure of the Children's Depression Inventory: Testing a latent trait-state model. Psychological Assessment, 17(2), 144-155. doi:10.1037/1040-3590.17.2.144

Cooper, G. D., Clements, P. T., \& Holt, K. (2011). A review and application of suicide prevention programs in high school settings. Issues in Mental Health Nursing, 32(11), 696-702. doi:10.3109/01612840.2011.597911

Cusimano, M. D., \& Sameem, M. (2011). The effectiveness of middle and high school-based suicide prevention programmes for adolescents: A systematic review. Injury Prevention, 17(1), 43-49.

DeRosa, N., \& Logsdon, M. C. (2006). A comparison of screening instruments for depression in postpartum adolescents. Journal of Child and Adolescent Psychiatric Nursing, 19(1), 13-20. doi:10.1111/j.1744-6171.2006.00037.x

Ellonen, N., Kääriäinen, J., \& Autio, V. (2008). Adolescent depression and school social support: A multilevel analysis of a finnish sample. Journal of Community Psychology, 36(4), 552-567. doi:10.1002/jcop.20254

Goodwin, R. D., Kroenke, K., Hoven, C. W., \& Spitzer, R. L. (2003). Major depression, physical illness, and suicidal ideation in primary care. Psychosomatic Medicine, 65(4), 501-505. doi:10.1097/01

Gray, L. B., Dubin-Rhodin, A., Weller, R. A., \& Weller, E. B. (2009). Assessment of depression in children and adolescents. Current Psychiatry Reports, 11(2), 106-113.

Gusmão, R. M., Xavier, M., Heitor, M. J., Bento, A., \& Almeida, J. M. C. (2005). O peso das perturbações depressivas. Aspectos epidemiológicos globais e necessidades de informação em Portugal. Acta Médica Portuguesa, 18, 129-146.

Harrington, R. (2001). Depression, suicide and deliberate selfharm in adolescence. British Medical Bulletin, 57(1), 47-60. doi: $10.1093 / \mathrm{bmb} / 57.1 .47$

Jensen, P. S., Cheung, A., Zuckerbrut, R., Ghalib, K., \& Levitt, A. (2012). Guidelines for adolescent depression in primary care (GLAD-PC) Toolkit. (Reprinted from Pediatrics, 120, Copyright 2007 by the American Academy of Pediatrics).

Kessler, R. C., Avenevoli, S., \& Ries Merikangas, K. (2001). Mood disorders in children and adolescents: An epidemiologic perspective. Biological Psychiatry, 49(12), 1002-1014. doi:10.1016/S0006-3223(01)01129-5

Kline, T. (2005). Psychological testing: A practical approach to design and evaluation. Thousand Oaks, CA: Sage.

Kovacs, M. (1985). The Children's Depression Inventory (CDI). Psychopharmacology Bulletin, 21(4), 995-998.

Kutcher, S. P., \& Chehil, S. (2007a). Suicide risk management: A manual for health professionals. Oxford, UK: Blackwell Pub.

Kutcher, S., \& Chehil, S. (2007b). Gestão de risco de suicídio. Um manual para profissionais de saúde. Lisboa, Portugal: Lundbeck Institute Portugal.

Kutcher, S., \& Wei, Y. (2012). Mental health and the school environment: Secondary schools, promotion and pathways to care. Current Opinion in Psychiatry, 25(4), 311-316. doi:10.1097/YCO.0b013e3283543976

Leaf, P. J., Alegria, M., Cohen, P., Goodman, S. H., Horwitz, S. M., Hoven, C. W., ...Regier, D. A. (1996). Mental health service use in the community and schools: Results from the four-community MECA Study. Methods for the Epidemiology of Child and Adolescent Mental Disorders Study. Journal of the American Academy of Child \& Adolescent Psychiatry, 35(7), 889-897.

LeBlanc, J. C., Almudevar, A., Brooks, S. J., \& Kutcher, S. (2002). Screening for adolescent depression: Comparison of the Kutcher Adolescent Depression Scale with the Beck depression inventory. Journal of Child and Adolescent Psychopharmacology, 12(2), 113-126. doi:10.1089/104454602760219153

Lecrubier, Y., Sheehan, D. V., Weiller, E., Amorim, P., Bonora, I., \& Sheehan, K. H. (1997). The mini international neuropsychiatric interview (MINI): A short diagnostic structured interview: Reliability and validity according to the CIDI. European Journal of Psychiatry, 12, 224-231. doi:10.1016/ s0924-9338(97)83296-8

MacMillan, H. L., Patterson, C. J. S., Wathen, C. N., Feightner, J. W., Bessette, P., Elford, R. W., ...Canadian Task Force on Preventive Health Care. (2005). Screening for depression in primary care: Recommendation statement from Canadian Task Force on Preventive Health Care. Canadian Medical Association Journal, 172(1), 33-35.

Martins, A. Q. (2000). As manifestações clínicas da depressão na adolescência (Master thesis in Psychiatry and Mental Health, Universidade do Porto, Portugal).

Mojs, E., Warchol-Biederman, K., \& Samborski, W. (2012). Prevalence of depression and suicidal thoughts amongst university students in Poznan, Poland, preliminary report. Psychology, 3(2), 132-135. doi:10.4236/psych.2012.32020

Myers, K., \& Winters, N. C. (2002). Ten-year review of rating scales. II: Scales for internalizing disorders. Journal of the American Academy of Child and Adolescent Psychiatry, 41(6), 634-659. doi:10.1097/00004583-200206000-00004

Oliveira-Brochado, F., \& Oliveira-Brochado, A. (2008). Estudo da presença de sintomatologia depressiva na adolescência. Saude Mental, 26, 27-36.

Osman, A., Barrios, F. X., Gutierrez, P. M., Williams, J. E., \& Bailey, J. (2008). Psychometric properties of the Beck depression inventory - II in nonclinical adolescent samples. Journal of Clinical Psychology, 64, 83-102.

Pullen, L. M., Modrcin-McCarthy, M. A., \& Graf, E. V. (2000). Adolescent depression: Important facts that matter. Journal of Child and Adolescent Psychiatric Nursing, 13(2), 69-75.

Saluja, G., Lachan, R., Scheidt, P. C., Overpeck, M. D., Sun, W., \& Giedd, J. N. (2004). Prevalence of and risk factors for depressive symptoms among young adolescents. Archives of Pediatrics \& Adolescent Medicine, 158(8), 760-765.

Scott, M., Wilcox, H., Huo, Y., Turner, J. B., Fisher, P., \& Shaffer, D. (2010). School-based screening for suicide risk: Balancing costs and benefits. American Journal of Public Health, 100(9), 1648-1652. doi:10.2105/AJPH.2009.175224

Wei, Y., \& Kutcher, S. (2012). International school mental health: Global approaches, global challenges, and global opportunities. Child and Adolescent Psychiatric Clinics of North America, 21(1), 11-27. doi:10.1016/j.chc.2011.09.005

World Health Organization, \& World Bank. (Eds.). (2011). World report on disability. Geneva, Switzerland: World Health Organization.

Williams, S. B., O’Connor, E. A., Eder, M., \& Whitlock, E. V. (2008). Screening for child and adolescent depression in primary care settings: A systematic evidence review for the US preventive services task force. Pediatrics, 4, e716-e735. doi:10.1542/peds.2008-2415 
Quintão, S., David, S., Gusmão, R. \& Kutcher, S. (2015). Contribution to the Validation of the Kutcher Adolescent.

\section{Appendix}

Portuguese KADS-6

Original version: LeBlanc et al., 2002.

Portuguese version: Kutcher and Chehil, 2007b.

Na última semana, como estiveste "na média" ou "geralmente" em relação aos seguintes itens:

\begin{tabular}{ccccc}
\hline & 0 & 1 & 2 & 3 \\
Quase & Munca & tempo & A maior parte & O tempo \\
do tempo & todo \\
\hline
\end{tabular}

1. Mau humor, tristeza, sentindo-se sem graça ou mal, deprimido, simplesmente não pode ser perturbado.

2. Sentimentos de não ter valor, não ter esperança, deixar os outros tristes, não ser uma pessoa boa.

3. Sentindo-se cansado, fatigado, com pouca energia, com dificuldade para ficar motivado, tem que se esforçar para fazer as coisas, quer descansar ou ficar deitado.

4. Sentindo que a vida não é muito divertida, não se sentindo bem quando normalmente (antes de ficar doente) se sentiria bem, não sentindo tanto prazer com coisas divertidas como normalmente (antes de ficar doente).

5. Sentindo-se preocupado, nervoso, em pânico, tenso, excitado, ansioso.

6. Pensamentos, planos ou ações sobre suicídio ou de causar dano a si mesmo. 